\title{
The Implementation of Temperature and Humidity Automatic Control System for the Supermarket Fruits and Vegetables
}

\author{
Biqing $\mathrm{Li}^{1, \text { a }}$, Zhao $\mathrm{Li}^{2}, \mathrm{~b}^{,}{ }^{*}$, Hongyan Zhang ${ }^{1, \text { a }}$ \\ ${ }^{1}$ School of Information and Communication Engineering, He Zhou University, He Zhou Guangxi \\ 542899, China; \\ 2 Management Engineering Department, Guangxi Vocational and Technical College of \\ Communications, Nanning Guangxi 545000, China; \\ ajanliful@163.com, b229292710@qq.com
}

\begin{abstract}
Keywords: Temperature and humidity automatic control; STC89C52; Mobile terminal control; LCD1602 liquid crystal
\end{abstract}

\begin{abstract}
By setting the detection threshold of temperature and humidity, inspection of the supermarket counters, temperature and humidity environment safety , and display the upper and lower threshold and temperature and humidity data at the time through LCD1602, realize compare the temperature and humidity data has be test, if the data is beyond the security threshold, GSM module send text messages to the user, cell phone, and automatic control the environment adjust module to adjust temperature and humidity environment, the user can also control environment adjust module through mobile. This design has the ability to process the data, high precision, applicable widely, etc.
\end{abstract}

\section{Introduction}

This design elaborates the design of the automatic control system of temperature and humidity in the supermarket. Through the program demonstration, the best program can be finally selected by reference comparison. The interior environment of supermarket counter is collected and processed in this design. With STC89C52 as the core of design control, the collection of temperature and humidity was realized by using the DHT11 temperature and humidity module, and the data collected by LCD1602. The GSM module sent the alarm to the user's mobile phone.

\section{Project Demonstration}

The use of early AT89C51 microcontroller as the main control of the hardware system. It has 4K internal program memory, Flash reprogramming. And McS-51 single-chip microcomputers are fully compatible, however, due to the large storage space of the designed program, the AT89C51 chip may not meet the requirements, and the operation speed of AT89C51 is slower than that of the STC series.

\subsection{Display Section}

Scheme 1: using eight digital tubes to show the data, because it needs to be added to an external circuit, which makes the design more sophisticated.

Scheme 2: LCD 1602 is used for display data, this liquid crystal display has 16 by 2 byte display function, and the display is clear.

To sum up, LCD1602 is not just a function of eight digital tubes, but it's convenient to use LCD1602 as a display of hardware in this design. 


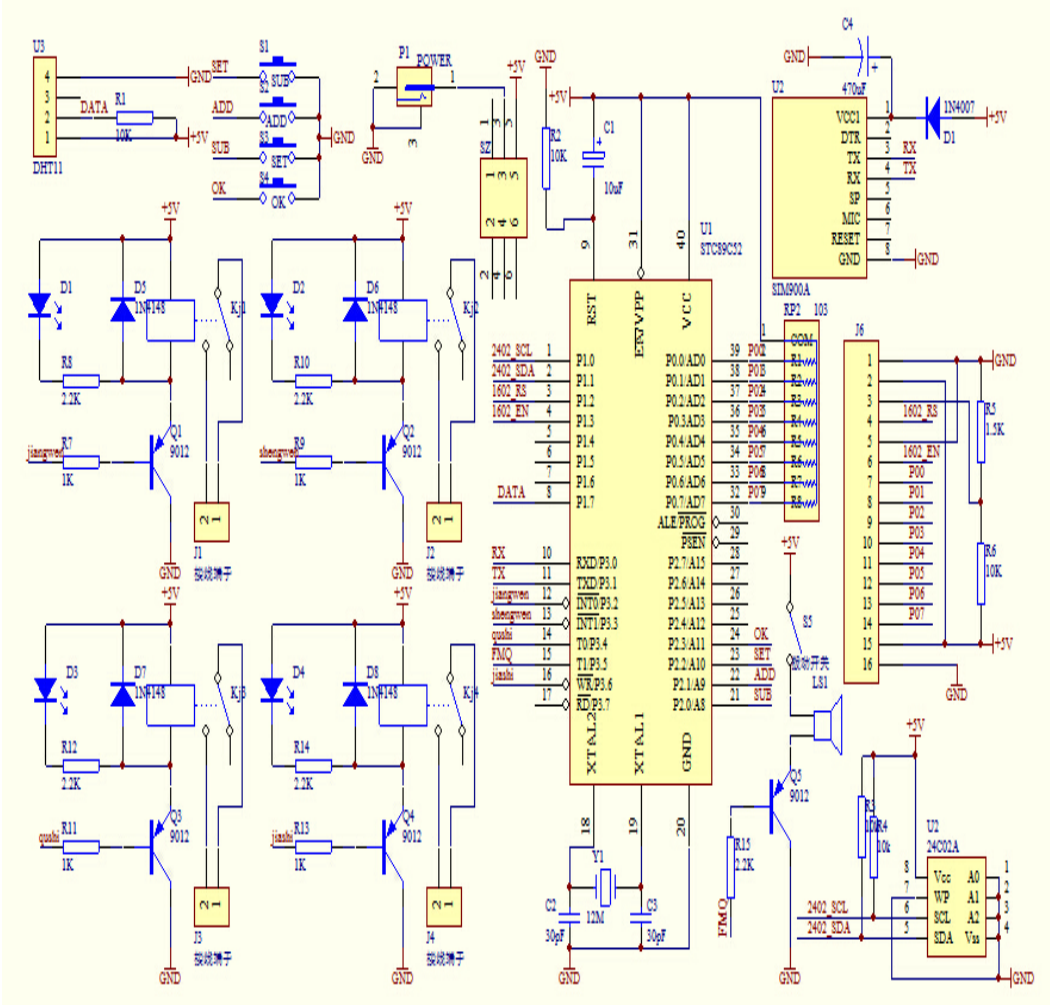

Figure 1 Display section

STC89C52 single chip has the following main performance.

Main performance:

(1) Working voltage: $3.3 \mathrm{~V} \sim 5.5 \mathrm{~V}$;

(2) Integration of a 4KB FLASH memory that can be programmed/erased 1000 times;

(3) Data can be kept for 10 years;

(4) You can choose 6 clocks or 12 clocks;

(5) The full-static design and the clock frequency range is 0 to $24 \mathrm{MHZ} / 33 \mathrm{MHZ}$;

(6) The confidentiality has three program memories;

(7) RAM with a memory size of 128 by 8 bytes;

(8) The I/O entrance line can be programmed with 32 pieces;

(9) It has two interrupt sources and five interrupt priorities;

(10) There are programmable serial channels;

(11) There are four working modes for all duplex serial ports;

(12) Low-functioning standby mode and power down operation mode;

(13) Intra-chip oscillator and clock circuit.

Reset circuit

The reset circuit provides reset function for STC89C52 single chip microcomputer. When the key SW-PB is pressed, the RST foot of the MCU can be provided with corresponding reset low level signal. The circuit connection is shown in figure 5. 


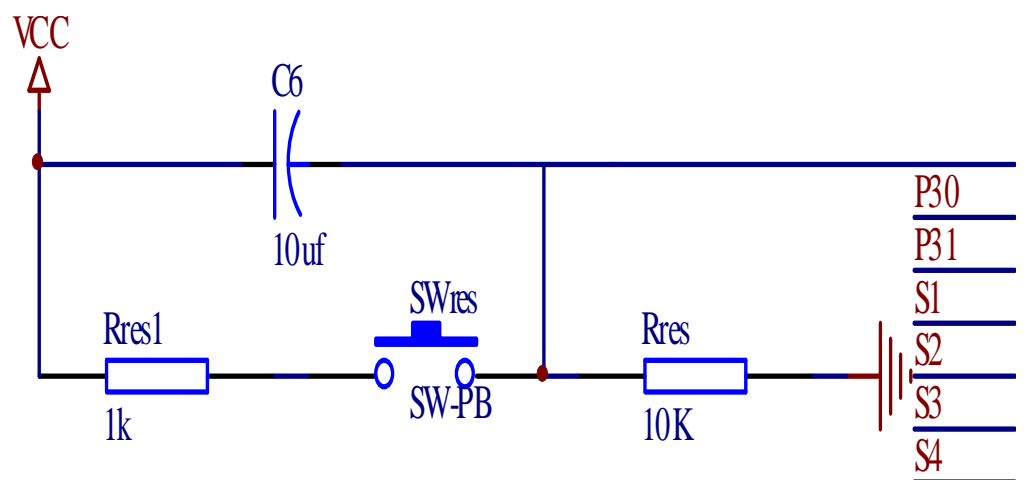

Figure 2. Reset circuit

The reset is in fact the single chip microcomputer initialization, in this application, the reset operation is ever-present. Whether the single chip is connected to the power supply at the beginning, or the system deadlock occurred during the execution of the single chip, or when the operation is not correct, the system should be reset to restore the system to normal. The function of the reset circuit is to restore the state of each circuit to a certain initial state. The reset condition of the single-chip microcomputer: the high potential of two (or more) machine cycles must be maintained on the reset pin. The reset form of single - chip microcomputer is composed of two parts: power-on reset and button reset. In the power-on reset circuit, the capacitor is charged to generate a reset. At the moment when the power is turned on, the potential at the reset pin is high (Vcc). After the power is turned on, the capacitor is rapidly charged as the charging proceeds, the potential at the reset pin will also gradually decrease to a low level. If there is a high level greater than 2 machine cycle times on the reset pin, the power-on reset function will be implemented. Button reset circuit, is the reset capacitor in parallel with a key switch. If users press the reset button when MCU is in working, the capacitor that has been previously charged immediately discharges through the resistor loop. The low voltage on the reset pin immediately goes high, and the high voltage remains high until the reset button is released, allowing the microcontroller reset conditions to achieve button reset.

Table 1 main AT control instructions.

\begin{tabular}{|c|c|}
\hline The AT command & Command interpretation \\
\hline AT+CMGF=1 & $\begin{array}{c}\text { Set short message format, parameter "1" indicates that the } \\
\text { short message system enters text mode. }\end{array}$ \\
\hline AT+CSCS=,GSM & $\begin{array}{c}\text { Set the character set to be used by the module, and "GSM" } \\
\text { represents the default standard of 7 bits for GSM. }\end{array}$ \\
\hline AT+CMGS=,*********, & Set the receiver's phone number. \\
\hline AT+CMGR=** & Read the text message and the parameter is the text location. \\
\hline AT+CGCLASS="B" & $\begin{array}{c}\text { GPRS mobile, "B" for terminal support package exchange } \\
\text { and data exchange. }\end{array}$ \\
\hline AT+CGDCONT=1,"IP","CMNET" & $\begin{array}{c}\text { Define the PDP context, set the Internet protocol and access } \\
\text { point. }\end{array}$ \\
\hline AT+CGATT=1 & Attach terminal to GPRS business. \\
\hline AT+CIPCSGP=1,"CMNET" & Set the GPRS connection mode. \\
\hline AT+CIPSTART="TCP","202.118.67.200","50000" & $\begin{array}{c}\text { Set up a TCP connection, parameters for each other's IP and } \\
\text { port slogans. }\end{array}$ \\
\hline AT+CIPSEND & Send the data. \\
\hline
\end{tabular}




\section{Production, Debugging and Performance Analysis.}

\subsection{Software Debugging}

First, the schematic diagram is drawn on protel99se, and the corresponding elements are found on proteus according to the schematic diagram. The parameter values of the elements (such as crystal oscillator, resistance, etc.) are set up, and the circuit is connected for simulation.

The program of STC89C52 single chip is written on the compilation software of keil3. According to the requirements of the design, after the compilation program is finished without error in running, the compiled program files are downloaded to proteus and the schematic diagram is simulated in proteus. Through the feedback of simulation results, the schematic diagram and program are modified continuously until satisfactory results are obtained from the simulation software. After the simulation is successful, continue to generate hex file on keil3, and enter this hex file into the SCM.

\subsection{Hardware Production and Debugging.}

After the success of the simulation, it begins to build software on the Protel99se hardware and made a picture of the design of the circuit, and then make a PCB diagram according to the schematic diagram to print it on a copper plate, and then start a hardware test after the corroboration and welding.

\subsection{Result and Analysis}

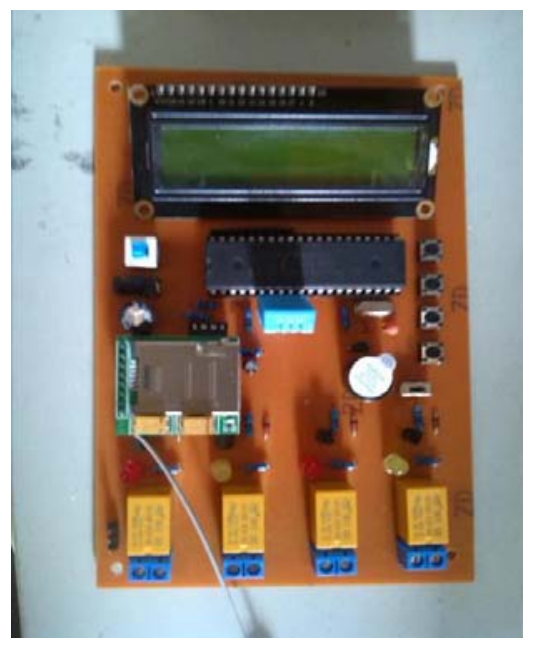

Figure 3 Hardware production

After the overall debugging, the design has met the requirements of graduation design, that is, the system can carry out data collection, analysis and processing of the supermarket counter, displaying the current temperature and humidity data. When the environment is in an unsafe range, the buzzer calls the alarm, and sends a text message to the predetermined cell phone. It can realize the opening of the automatic control relay to adjust the environment and can operate the phone to remotely control four relays to achieve the goal of controlling the environment.

Part of code as follow,

void main()

$\{$ uint $\mathrm{i}, \mathrm{j}$, testnum;

$\mathrm{EA}=0$;

Timer0_Init();

Data_Init();

Uart_init();

$\mathrm{EA}=1$;

L1602_init();

L1602_string(1,1," Welcome to T\&H ");

L1602_string(2,1," Control System!");

for $(\mathrm{i}=0 ; \mathrm{i}<1000 ; \mathrm{i}++)$

for $(\mathrm{j}=0 ; \mathrm{j}<1000 ; \mathrm{j}++)\{;\}$

L1602_string(1,1," "); 
L1602_string(2,1," ");

L1602_string(1,1,"Tem: C Hum: \%");

L1602_string(2,1,"Good environment");

$\mathrm{TH}=$ rdeeprom $(0)$;

Delay1(20);

TL=rdeeprom(1);

Delay1(20);

$\mathrm{HH}=$ rdeeprom(2);

Delay1(20);

$\mathrm{HL}=$ rdeeprom(3);

SendString("ati\rın");

delayms_1000ms();

delayms_1000ms();

SendString("AT+CMGF=1\r\n");

delayms_1000ms();

delayms_1000ms();

flag_1=1;

flag_2=1;

while(1)

$\{\quad$ if $($ FlagStartRH $==1) \quad\{$

TR0 = 0;

testnum = RH();

FlagStartRH = 0;

TR0 = 1;

humidity = U8RH_data_H;

temperature = U8T_data_H;

if $($ Mode $==0$ )

if (temperature $>\mathrm{TH}$ )

$\{\quad$ Led_jiangwen $=0$;

hot $=1$;

Led_shengwen $=1$;

cold $=0$;

else if(temperature $<$ TL)

\{ $\quad$ cold $=1$;

Led_jiangwen $=1$;

hot $=0$;

buzz $=0$;

else

Led_jiangwen=1;

Led_shengwen $=1$;

hot $=0$;

cold $=0$;

buzz $=1$;

if (humidity > $\mathrm{HH}$ )

\{ humid $=1$;

Led_jiashi $=1$;

dry $=0$;

else if(humidity $<$ HL)

$\{\quad$ dry $=1$;

Led_qushi $=1$;

humid=0;

else

\{ 


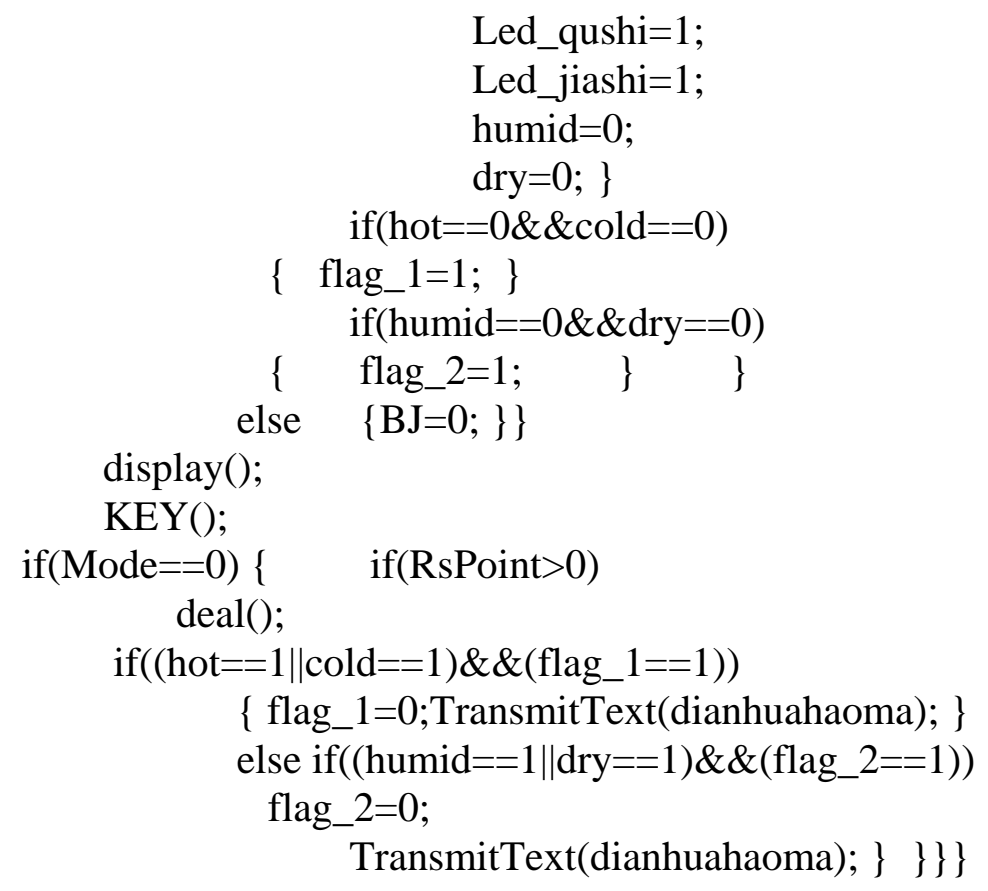

\section{Conclusion}

The temperature and humidity automatic control system of the supermarket is controlled by STC89C52 single chip microcomputer as the main control chip. The DHT11 temperature and humidity sensor is responsible for detecting the internal temperature and humidity environment of the special cabinet, and LCD1602 liquid crystal display is used to display the collected environmental data. The key module is used to set the value of the detected safety valve; the function of the GSM module is to send the temperature and humidity abnormal alarm to the user.

This work is supported the following fund :

2017 The student work subject program of Hezhou university:,college students' network addiction of the student work service research,(No,hzxysz201707).

2016 The higher education research subject project project of Hezhou university:,between collaborative innovation research of entrepreneurial talent cultivation system,.

2016 Guangxi university scientific research project::,Study on image processing based on digital compression sensing theory of intelligent robot,(No,KY2016YB454).

2017 college students' innovative entrepreneurial project:,The agricultural robot autonomous operations research based on machine vision,(No,201711838096) \&\&,Multi-functional autonomous agriculture robot development,(No,201711838121) \&\&,Research and development of navigation system for agricultural robot,(No,201711838008) \&\&,Research and development of data acquisition system and servo control system for mobile platform of agricultural robot, (No,201711838075) \&\&,Research and development of visual navigation system for agricultural robot test platform,(No,201711838076).

2017 Guangxi education science 'ten-three-five' planning project:,Based on zte's ICT education platform of fusion, work-integrated learning education training mode research,(No,2017B107).

\section{References}

[1]. B.Q LI, Y.F LING, H.Y ZHANG, S.Y ZHENG: The Design and Realization of Cherry Tomato Harvesting Robot Based on IOT. International Journal of Online Engineering, 12(12), 23, (2016).

[2]. B.Q LI, W.L GUAN, S.Y ZHENG, X.G Yue: OPTIMISATION DESIGN OF CORN PRECISION SEEDER BASED ON MULTI-ROUTE AND MULTI-CHANNEL CONTROL. JOURNAL OF THE BALKAN TRIBOLOGICAL ASSOCIATION, 21(4A), 1215, (2015). 
[3]. B.Q LI, X.M YANG GUAN, S.Y ZHENG,Internet of Things-based Simulation Study on Lijiang River Water Environment Monitoring. Journal of Coastal Research,79, 1-5, (2017).

[4]. B.Q Li, et al, Intelligent Control Management System and Its Application, in: PROCEEDINGS OF THE 2016 INTERNATIONAL CONFERENCE ON ECONOMICS AND MANAGEMENT INNOVATIONS, Wuhan, China, 2016, PP.68-71.

[5]. B.Q Li, et al, Design and Implementation of Tanks War Game Based on the Android Platform, in: PROCEEDINGS OF THE 2016 2ND WROKSHOP ON ADVANCED RESEARCH AND TECHNOLOGY IN INDUSTRY APPLICATIONS, Dalian, China, 2016, PP.963-966.

[6]. B.Q Li, et al, Design of a Tea Garden Antifreezing Control System, in: PROCEEDINGS OF THE 2016 6TH INTERNATIONAL CONFERENCE ON MACHINERY, MATERIALS, ENVIRONMENT, BIOTECHNOLOGY AND COMPUTER (MMEBC), Tianjin, China, 2016, PP.736-738.

[7]. B.Q Li, et al, Design of Electronic Compass, in: PROCEEDINGS OF THE 2016 6TH INTERNATIONAL CONFERENCE ON MACHINERY, MATERIALS, ENVIRONMENT, BIOTECHNOLOGY AND COMPUTER (MMEBC), Tianjin, China, 2016, PP.1240-1243.

[8]. B.Q Li, et al, Research of Automatically Light-Adjusting Lamp, in: PROCEEDINGS OF THE 2016 INTERNATIONAL CONFERENCE ON COMPUTER ENGINEERING, INFORMATION SCIENCE \& APPLICATION TECHNOLOGY (ICCIA 2016), Guilin, China, 2016, PP.249-252.

[9]. B.Q Li, et al, The Design and Realization of Fruit Harvesting Robot Based on IOT, in: PROCEEDINGS OF THE 2016 INTERNATIONAL CONFERENCE ON COMPUTER ENGINEERING,INFORMATION SCIENCE \& APPLICATION TECHNOLOGY (ICCIA 2016), Guilin, China, 2016, PP.261-264.

[10]. B.Q Li, et al, A New Type of Automatic Opening and Closing Light-Operated Curtain, in: PROCEEDINGS OF THE 2016 INTERNATIONAL CONFERENCE ON MECHATRONICS ENGINEERING AND INFORMATION TECHNOLOGY (ICMEIT), Xian, China, 2016, PP.66-69.

[11]. B.Q Li, et al, Design of the Intelligent Air Humidifier, in: PROCEEDINGS OF THE 2016 INTERNATIONAL CONFERENCE ON MECHATRONICS ENGINEERING AND INFORMATION TECHNOLOGY (ICMEIT), Xian, China, 2016, PP.201-203.

[12]. B.Q Li, et al, The Design Implementation of the APP of Experiencing Guangxi Folk Custom, in: PROCEEDINGS OF THE 2016 INTERNATIONAL CONFERENCE ON ECONOMICS AND MANAGEMENT INNOVATIONS, Wuhan, China, 2016, PP.47-50.

[13]. S.Y Zheng, et al, Digital Display Design of Ethnic Clothing of Nanling, in: PROCEEDINGS OF THE 4TH INTERNATIONAL CONFERENCE ON MECHATRONICS, MATERIALS. CHEMISTRY AND COMPUTER ENGINEERING 2015(ICMMCCE 2015), Xian, China, 2015, PP.2805-2808.

[14]. S.Y Zheng, et al, Design and Implementation of Supermarket Personnel Management System Based On Java, in: PROCEEDINGS OF THE 2015 INTERNATIONAL CONFERENCE ON EDEDUCATION,MANAGEMENT AND COMPUTING TECHNOLOGY(ICEMCT-16), Hangzhou, China, 2016, PP.957-960.

[15]. S.Y Zheng, et al, Brief analysis on,HeYuanTong, Campus Mobile Phone APP Design, in: PROCEEDINGS OF THE 2015 5TH INTERNATIONAL CONFERENCE ON COMPUTER SCIENCES AND AUTOMATION ENGINEERING, Sanya, China, 2015, PP.151-154. 
[16]. S.Y Zheng, et al, Social Work in Teen Addiction Correction Services Research Under the New Situation, in: PROCEEDINGS OF THE 2015 4TH NATIONAL CONFERENCE ON ELECTRICAL, ELECTRONICS AND COMPUTER ENGINEEERING (NCEECE 2015), Xian, China, 2015, PP.252-255.

[17]. B.Q Li, et al, The Design of Remote Temperature Monitoring System, in: International Conference on Green Energy and Sustainable Development, MAY 27-28, 2017, PP.20-22.

[18]. B.Q Li, et al, Design of Portable Valuables Touch Alarm Circuit,in: International Conference on Advances in Materials, Machinery, Electronics ,2017, PP.27-32.

[19]. B.Q Li, et al, Design and Implementation of a Simple Acousto Optic Dual Control Circuit, in:5th International Conference on Computer-Aided Design, Manufacturing, Modeling and Simulation,2017, PP.78-80.

[20]. B.Q Li, et al, Design of electronic lock based on single-chip microcomputer,in:4th International Conference on Electrical and Electronics Engineering and Computer Science ,2017, PP.55-60.

[21]. B.Q Li, et al, The Design of Chicken House Electronic Intelligent Lighting Apparatus, in: International Conference on Mechanical, Electronic, Control and Automation Engineering, 2017, PP.15-20.

[22]. B.Q Li, et al, Office Automation Sub-Summary of the Work and the Project Management System, in: International Conference on Mechanical, Electronic, Control and Automation Engineering, 2017, PP.46-48.

[23]. B.Q Li, et al, The Design of Intelligent Heat Dissipator Control Circuit, in: PROCEEDINGS OF THE 2017 2ND INTERNATIONAL CONFERENCE ON MATERIALS SCIENCE, MACHINERY AND ENERGY ENGINEERING, 2017, PP.22-25.

[24]. B.Q Li, et al, The Design of IPv6's Transitional Scheme in University, in: International Conference on Materials Science, Energy Technology, Power Engineering (MEP), 2017, PP.91-93.

[25]. B.Q Li, et al, The Personal Receiving Document Management and the Realization of Email Function in OAS,in:International Conference on Materials Science, Energy Technology, Power Engineering (MEP) ,2017, PP.121-123.

[26]. S.Y Zheng, et al, Design and Implementation of an Audio Indicator,in: 5th International Conference on Computer-Aided Design, Manufacturing, Modeling and Simulation,2017, PP.21-23.

[27]. S.Y Zheng, et al, Implementation and Application of ACL in Campus Network, in: International Conference on Advances in Materials, Machinery, Electronics, 2017, PP.151-153.

[28]. S.Y Zheng, et al, The Design of Liquid Drip Speed Monitoring Device System Based on MCU, in: International Conference on Green Energy and Sustainable Development, MAY 27-28, 2017, PP.51-53.

[29]. S.Y Zheng, et al, The Design of Hearing and hypnosis all-in-one Machine, in: International Conference on Mechanical, Electronic, Control and Automation Engineering, 2017, PP.66-68.

[30]. S.Y Zheng, et al, Campus Network Security Defense Strategy, in: International Conference on Mechanical, Electronic, Control and Automation Engineering, 2017, PP.30-33. 
[31]. S.Y Zheng, et al, Design and implementation of multifunctional charger,in: International Conference on Materials Science, Energy Technology, Power Engineering (MEP) ,2017, PP.71-73. 